\title{
The Demographic Effects of Katrina: An Impact Analysis Perspective
}

\author{
David A. Swanson ${ }^{1, *}$, Jerome N. McKibben ${ }^{2}$, Lynn Wombold ${ }^{3}$, Richard G. Forgette ${ }^{4}$ and Mark V. \\ Van Boening
}

\author{
${ }^{I}$ Department of Sociology, University of California Riverside, Riverside, CA 92521, USA \\ ${ }^{2}$ McKibben Demographic Research, P.O. Box 2921, Rock Hill, SC 29732, USA \\ ${ }^{3}$ ESRI, 380 New York Street, Redlands, CA 92373-8100, USA \\ ${ }^{4}$ Department of Political Science, University of Mississippi, University, MS 38677-1848, USA \\ ${ }^{5}$ Department of Economics, University of Mississippi, University, MS 38677-1848, USA
}

\begin{abstract}
This paper examines the effect of Hurricane Katrina on the populations of 79 ZIP code areas in Louisiana (55) and Mississippi (24) devastated by the hurricane. We compare pre-Katrina population projections for 2007 with postKatrina projections for 2007 and 2010 and estimate that Katrina reduced the area's population by 311,150 people (21.2\%) from the 1,464,280 expected in the absence of Katrina. We also find a striking difference between Louisiana and Mississippi. In the 55 Louisiana ZIP codes, the black population was reduced both absolutely and relatively more than the white population (loss of 150,032 blacks v. 107,845 whites, or 32.7\% v. 19.8\%). In contrast, the white population in the 24 Mississippi ZIP codes was reduced both absolutely and relatively more than the black population $(28,812$ whites or $10.3 \% \mathrm{v}$. 5,003 blacks or $6.3 \%$ ). Our analysis suggests that Katrina's demographic effects are profound, and may persist well beyond the 2010 U.S. Census.
\end{abstract}

\section{INTRODUCTION}

At the time of its August $29^{\text {th }}, 2005$ landfall on the Louisiana and Mississippi Gulf Coast, Hurricane Katrina represented the one of the greatest natural disasters in American history. The geographic impact extended over 90,000 square miles, roughly the size of Great Britain, and at least 1,836 people lost their lives [1]. Swanson et al. observe that while such numbers are staggering and generally accurate, they are only estimates of Katrina's actual impact; complete counts in the wake of large-scale disasters are typically impossible due to the ephemeral nature of the data and the high cost of collecting it [2]. Unfortunately, many of these estimates are not informed by on-the-ground research, exceptions to this being those developed by Swanson [3] and Swanson et al. [2].

In many ways, Hurricane Katrina represents two distinct disasters, natural and man-made $[4,5]$. Van Heerden and Bryan attribute the flooding that affected New Orleans and surrounding areas to a series of human errors [5]. They also argue convincingly that the disastrous waves that hit the coast of Mississippi originated in part along the eastern side of the Mississippi River Levee. As Katrina approached landfall, it pushed massive amounts of water in front of itself. Van Heerden and Bryan contend that these waters were held in place by the levee instead of being allowed to flow back

*Address correspondence to this author at the Department of Sociology, University of California Riverside, Riverside, CA 92521, USA; Tel: 951 827 4373; Fax: 951827 3330; E-mail: David.swanson@ucr.edu out into the Gulf of Mexico and that once the hurricane eye moved over Lake Borgne, northwest quadrant winds threw this piled-up water against the coast of Mississippi [5]. If this is true, the most damaging waves may not have been due to storm surge alone, but to effects from man-made structures as well. To the extent that these structures remain in place, future storms that follow a similar path may pose an equally dangerous threat to the Mississippi Gulf Coast population. It may also indicate that building higher and stronger levees in Louisiana - a current plan of action to assist New Orleans may exacerbate Mississippi's future storm damage even more.

The distinction between natural and man-made damage from Katrina is germane to our study, but it is not our primary focus. Instead, our research has two major aims. First, it complements Frey and Singer, who provided the first comprehensive demographic portrait of the effects of hurricanes Katrina and Rita on Gulf Coast populations in the 117 counties comprising the FEMA-designated disaster area [6]. We contribute to this portrait by examining the twenty-four ZIP code areas in three Mississippi counties (Hancock, Harrison, and Jackson) and the fifty-five ZIP codes in five Louisiana parishes (Jefferson, Orleans, Plaquemines, St. Bernard, and St. Charles) that bore the brunt of Katrina's impact. Similar to Frey and Singer [6], we use a perspective adopted from socio-economic impact analysis [7]. Second, we extend the work of Swanson [3], who examined the effect of Katrina on the populations of twenty ZIP codes that were at the epicenter of Katrina's landfall on the Mississippi Gulf Coast. We extend his analysis to the entire area affected 


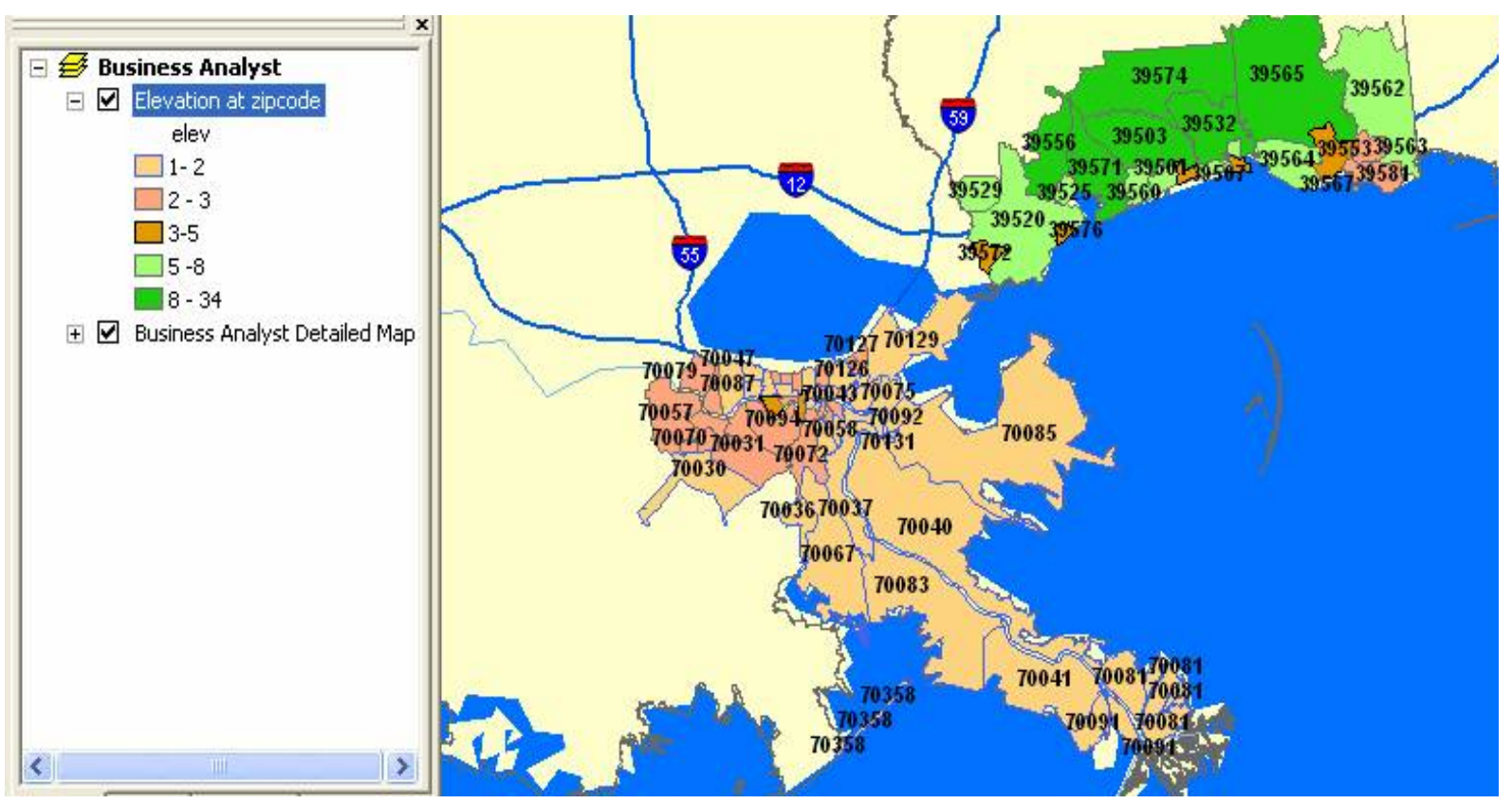

Fig. (1). The 79 zip code areas by elevation.

by Katrina by applying the same "impact" perspective and by examining population changes at the county/parish levels of geography for these same areas.

Analysis at the ZIP code level is useful for two reasons. First, ZIP codes are used by many private and public sector entities for planning [8-12]. Second, ZIP codes provide a high enough level of geographical aggregation so as to provide meaningful statistical estimates and they provided a low enough geographical aggregation to provide a fairly precise identification of the area most devastated by Katrina's landfall. In particular, there were seventy-nine ZIP codes at or near the epicenter of Hurricane Katrina, with fifty-five in Louisiana and twenty-four in Mississippi. The fifty-five ZIP codes in Louisiana cover areas in New Orleans and immediate environs that were severely affected by flooding. The twenty-four ZIP codes in Mississippi cover the Mississippi Gulf Coast from Alabama to Louisiana in an area extending north from the Gulf Coast approximately fifteen miles. These areas were largely affected by a combination of wind and storm surge, although the combination varied according to proximity to the Gulf (including the Bay of St. Louis) and waterways leading from the Gulf [5]. A representation of the study area is provided in Fig. (1), which shows all 79 ZIP codes and their elevations.

As noted earlier, we utilize a variation on Swanson's "impact" perspective [3]. Specifically, we compare the estimated demographic effects of Katrina with estimates that are made in the absence of Katrina. It is a variation of the impact perspective because socio-economic and environment impact analyses are typically done in advance of a planned impact, not after the fact [7, 13-17]. However, in the case of an unplanned event like Katrina, the concepts, perspectives, and tools of impact assessment prove to be very useful. This is important because Swanson found that such a comparison for Katrina-impacted counties in Mississippi suggested that Katrina's demographic effects are profound and not only likely to affect the 2010 census counts in these areas, but that they may persist well beyond [3].

Before describing the data and methods used in this study, it is worthwhile to note here what is meant by the post-disaster phases of rescue, relief, and recovery/ rehabilitation. The definitions provided by the Asian Disaster Reduction Center are used for this purpose [18]. We begin with the "rescue phase," which usually consists of a forty-eight hour period immediately following a disaster in which local people and trained professionals attempt to save lives among the affected population. When rescue operations end, the relief phase begins in which food, water, clothing, medical supplies, shelters, and other elements associated with basic survival are delivered to the affected population. This phase usually lasts between one to three months. In the recovery/rehabilitation phase, social, economic and other infrastructures are restored and the economy revitalized. In the short term, debris clearing and removal usually takes place, while in the longer term, rebuilding is undertaken. This phase usually lasts for one to several years, but can be as long as five years. Because we are examining the impact of Katrina approximately two years after it struck, our analysis views the demographic impacts of Katrina into the recovery/ rehabilitation phase.

\section{DATA AND METHODS}

The 2007 "baseline" population estimates made in the absence of Katrina are found by interpolating between 2005 estimates and 2010 projections developed by ESRI prior to Katrina [19]. The 2007 Katrina-impacted population estimates were developed by ESRI from the initial 2006 estimates of the effects of Katrina [20]. Although several information "post-census" sources are used to re-calibrate the baseline projections, they were produced using the cohortcomponent method, which is a standard population projection method [21]. In generating these projections, census 2000 data were used as the launch year while trends between 
the 1990 and 2000 censuses were used to generate preliminary projections. The preliminary projections were, in turn, revised using information that is symptomatic of population change that became available after the 2000 through to July $1^{\text {st }}, 2005$, which is just prior to the landfall of Katrina.

The 2007 Katrina-impacted estimates represent the baseline projections that were informed by additional information specific to Katrina. To quantify the damage to housing and the displacement of population, ESRI applied FEMA data, which included maps of the impacted areas, damage polygons, and summary counts of applicants for FEMA assistance. Beginning with the damage polygons that FEMA compiled from surveys and aerial photographs of damaged areas after the storms, the first step was to assign the damage polygons to census blocks in order to link the damage assessment to demographic data. When a block was linked to multiple damage codes, manual review was used to assign a unique damage code to the block. The block tables were merged with Census 2000 block data (revised), aggregated by damage code and block group, and applied to ESRI's 2005 block group updates to estimate population, households, and housing units by damage code.

Damage assessments from FEMA ranged from "catastrophic" to "limited" or "possible flooding". To associate the condition of the housing with population displacement, field work was used. "Catastrophic" or "extensive" damage is obvious - homes are destroyed or uninhabitable. However, damage due to "flooding" or "possible flooding" is not as apparent. The homes are still standing. Similarly, "moderate" or "limited" damage do not necessarily imply that homes are uninhabitable or that the residents have left. Neighborhoods in Orleans, St. Bernard and Plaquemines Parishes and Hancock County in Mississippi were surveyed in February 2006 to determine if the damage codes were realistic, the residents had returned, or progress on recovery was evident.

Final estimates of the damage assessments by population, households, and housing units were combined with summary counts from the U.S. Postal Service (USPS) National Change of Address file to estimate the households that left. USPS created special tabulations by ZIP codes specific to the Gulf Coast areas impacted by the 2005 hurricanes. The first file reflected households that had filed change of address forms by October 2005. The second file included change of address forms filed through December 2005.

However, out-migration is only half of the picture. To complete the population and household totals in 2006, the next step was to estimate the destination of evacuees, either returned to their homes or relocated elsewhere. The estimated destination of evacuees was based upon the USPS tabulation of destination from the change of address forms filed through December 2005. In-migration was calculated by county first and then apportioned to ZIP codes. Return migration to impacted areas was assumed to occur first in the areas with limited damage from the storms.

The characteristics of movers were developed from their points of origin, first by block and then by block group. Among the areas that experienced a net loss of population and households, the characteristics were calculated by applying ESRI's standard techniques for updating age, race and
Hispanic origin, income, etc., to the smaller population/household bases [22]. The estimated change in characteristics among destination areas was derived from the characteristics of the movers. Many evacuees tried to settle as close to their homes as possible, which created a major influx of evacuees in nearby towns. Under these circumstances, the evacuees could create significant changes in the profiles of destination communities.

Building from the initial 2006 estimates, the 2007 estimates of the Gulf Coast populations incorporate the usual sources of data, including postal delivery statistics released later in 2006 and 2007, to integrate past and current change in the distribution and characteristics of the population along the Gulf Coast [23].

The difference between the baseline projection interpolated to 2007 and the Katrina-impacted estimate for a given area is used to gauge the impact of Katrina. The authors argue that this is more appropriate that simply comparing postKatrina population estimates to pre-Katrina population data. A simple empirical example serves to illustrate this point.

Consider Mississippi Zipcode, 39525 (“Diamondhead”). In 2000 , there were 5,886 people counted in the decennial census and as of July $1^{\text {st }} 2005$, a population of 6,853 was estimated by ESRI. This Zipcode gained 967 people, an increase of $16.43 \%$ between 2000 and July $1^{\text {st }}, 2005$. The 2007 Katrina impacted-estimate for this Zipcode was 6,725 while the baseline projection interpolated to 2007 is 7,108 . If we subtract the 2005 estimate from the 2007 Katrina-impacted estimate, the result is a decline of 128 people ( -1.87 percent), which represents the effect of Katrina terms of the change between the Pre-Katrina 2005 population and the postKatrina 2007 population. By subtracting the 2007 Katrinaimpacted estimate from the 2007 baseline, the result is an decline of 383 people ( -5.39 percent), which represents the effect of Katrina relative to what was expected in 2007 in the absence of Katrina. The two measures of difference tell different stories for Zipcode 39525. We are not arguing that the comparison of post-disaster with pre-disaster is not useful; rather, we are pointing out that in many cases it may useful to compare what is found after a large scale disaster with what could have been instead of only comparing what is found relative to what was. The "impact" comparison we advocate is germane to two types of areas: (1) those that were experiencing population increases prior to a large scale disaster; and (2) those experiencing population losses. For areas that had growth rates of at or near zero prior to a large scale disaster, the two comparisons will result in the same difference. We believe that the impact perspective we use in this paper is particularly useful for areas subject to hurricanes because of the extensive growth these areas have experienced and are expected to continue experiencing [24].

\section{RESULTS}

\section{III.A. LOUISIANA}

As can be seen in Table 1, thirteen of the 55 impacted ZIP code areas in Louisiana experienced a relative loss of more than 50 percent of the population. Four of them are located either within or in direct proximity to New Orleans (70124, 70126, 70127, and 70043) and had more than a 70 percent loss. 
Table 1. 2007 Total Population Estimates by Parish, Place \& Zip Code in Louisiana: Difference Between Impact \& Baseline*

\begin{tabular}{|c|c|c|c|c|c|c|}
\hline \multirow{2}{*}{ PARISH } & \multirow{2}{*}{ ZIP CODE } & \multirow{2}{*}{ NAME } & \multicolumn{2}{|c|}{ Total Population Estimate } & \multicolumn{2}{|c|}{ Difference } \\
\hline & & & Impact & Baseline & Absolute & Percent \\
\hline Jefferson & 70001 & Metairie & 37,205 & 39,787 & $-2,582$ & $-6.49 \%$ \\
\hline Jefferson & 70002 & Metairie & 17,953 & 19,716 & $-1,763$ & $-8.94 \%$ \\
\hline Jefferson & 70003 & Metairie & 41,351 & 43,805 & $-2,454$ & $-5.60 \%$ \\
\hline Jefferson & 70005 & Metairie & 24,082 & 25,889 & $-1,807$ & $-6.98 \%$ \\
\hline Jefferson & 70006 & Metairie & 15,419 & 16,713 & $-1,294$ & $-7.74 \%$ \\
\hline Jefferson & 70036 & Barataria & 1,278 & 1,458 & -180 & $-12.35 \%$ \\
\hline Jefferson & 70053 & Gretna & 16,667 & 17,984 & $-1,317$ & $-7.32 \%$ \\
\hline Jefferson & 70056 & Gretna & 37,399 & 41,486 & $-4,087$ & $-9.85 \%$ \\
\hline Jefferson & 70058 & Harvey & 40,176 & 43,695 & $-3,519$ & $-8.05 \%$ \\
\hline Jefferson & 70062 & Kenner & 18,293 & 19,063 & -770 & $-4.04 \%$ \\
\hline Jefferson & 70065 & Kenner & 51,360 & 54,937 & $-3,577$ & $-6.51 \%$ \\
\hline Jefferson & 70067 & Lafitte & 4,395 & 4,808 & -413 & $-8.58 \%$ \\
\hline Jefferson & 70072 & Marrero & 56,932 & 58,172 & $-1,240$ & $-2.13 \%$ \\
\hline Jefferson & 70094 & Westwego & 34,300 & 34,903 & -603 & $-1.73 \%$ \\
\hline Jefferson & 70121 & New Orleans & 12,556 & 13,211 & -655 & $-4.96 \%$ \\
\hline Jefferson & 70123 & New Orleans & 26,408 & 28,232 & $-1,824$ & $-6.46 \%$ \\
\hline Jefferson & 70358 & Grand Isle & 1,408 & 1,435 & -27 & $-1.91 \%$ \\
\hline Orleans & 70112 & New Orleans & 3,298 & 6,441 & $-3,143$ & $-48.80 \%$ \\
\hline Orleans & 70113 & New Orleans & 6,162 & 10,204 & $-4,042$ & $-39.61 \%$ \\
\hline Orleans & 70114 & New Orleans & 28,591 & 28,300 & 291 & $1.03 \%$ \\
\hline Orleans & 70115 & New Orleans & 34,503 & 38,220 & $-3,717$ & $-9.72 \%$ \\
\hline Orleans & 70116 & New Orleans & 11,589 & 16,055 & $-4,466$ & $-27.82 \%$ \\
\hline Orleans & 70117 & New Orleans & 16,011 & 50,459 & $-34,448$ & $-68.27 \%$ \\
\hline Orleans & 70118 & New Orleans & 32,904 & 35,730 & $-2,826$ & $-7.91 \%$ \\
\hline Orleans & 70119 & New Orleans & 23,989 & 48,878 & $-24,889$ & $-50.92 \%$ \\
\hline Orleans & 70122 & New Orleans & 17,911 & 43,928 & $-26,017$ & $-59.23 \%$ \\
\hline Orleans & 70124 & New Orleans & 6,403 & 21,766 & $-15,363$ & $-70.58 \%$ \\
\hline Orleans & 70125 & New Orleans & 9,264 & 22,679 & $-13,415$ & $-59.15 \%$ \\
\hline Orleans & 70126 & New Orleans & 8,436 & 38,627 & $-30,191$ & $-78.16 \%$ \\
\hline Orleans & 70127 & New Orleans & 7,929 & 29,244 & $-21,315$ & $-72.89 \%$ \\
\hline Orleans & 70128 & New Orleans & 7,761 & 20,637 & $-12,876$ & $-62.39 \%$ \\
\hline Orleans & 70129 & New Orleans & 6,663 & 14,790 & $-8,127$ & $-54.95 \%$ \\
\hline Orleans & 70130 & New Orleans & 12,813 & 14,435 & $-1,622$ & $-11.24 \%$ \\
\hline Orleans & 70131 & New Orleans & 30,753 & 27,785 & 2,968 & $10.68 \%$ \\
\hline Orleans & 70148 & New Orleans & 0 & 0 & N/A & N/A \\
\hline Plaquemines & 70037 & Belle Chasse & 16,876 & 15,344 & 1,532 & $9.99 \%$ \\
\hline
\end{tabular}


Table 1. cond...

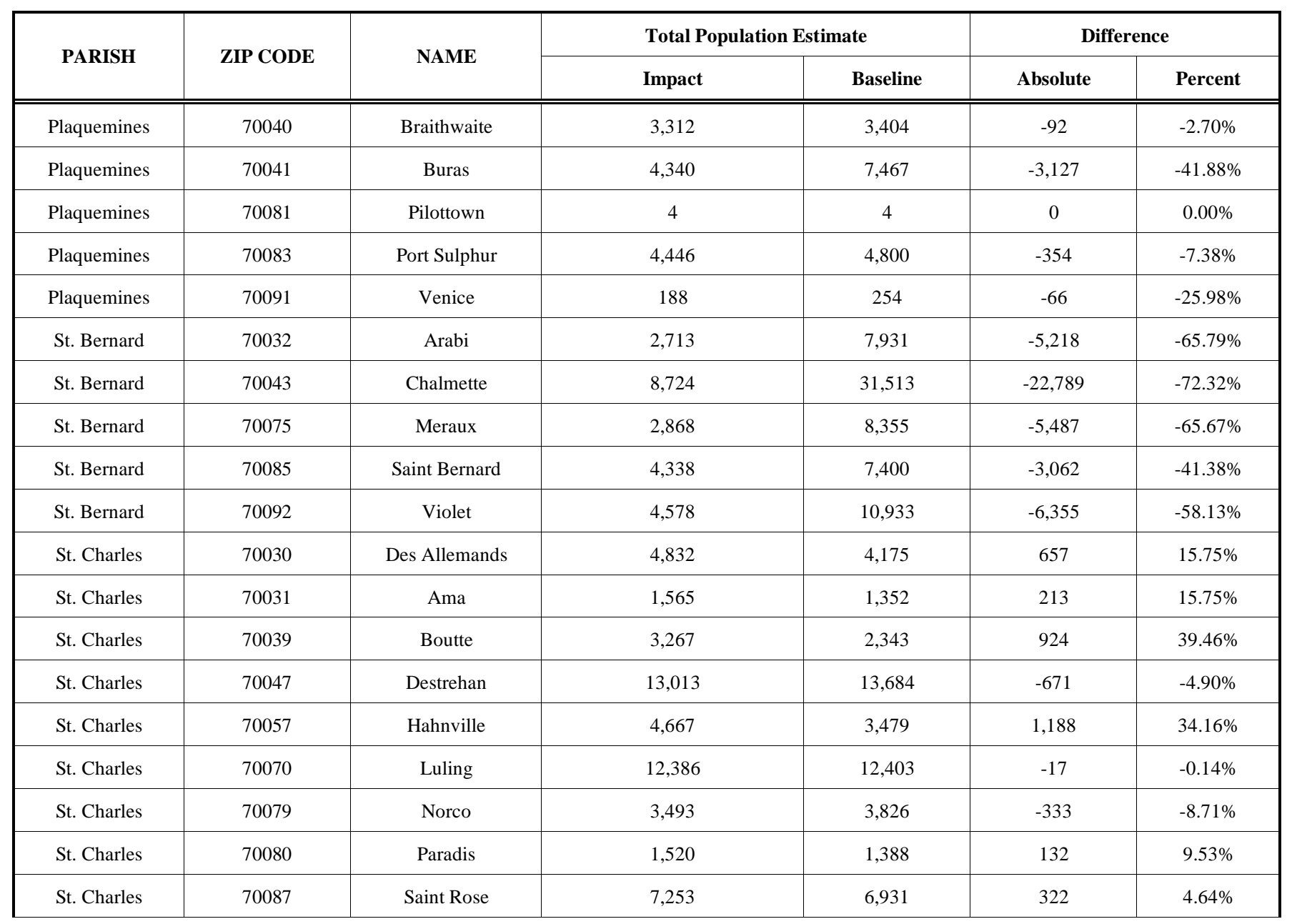

*Numbers are subject to rounding.

Table 2. 2007 Total Population Estimates by Parish in Louisiana: Difference Between Impact \& Baseline*

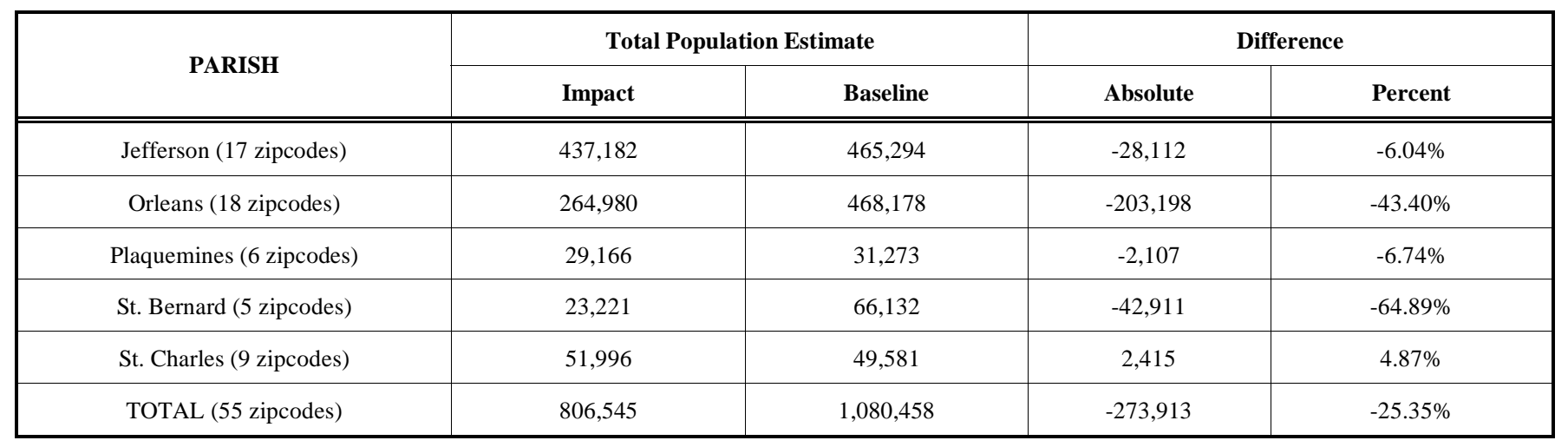

* Parish values may not sum precisely to TOTAL because of rounding.

In total, we estimate that Katrina reduced the population of the 55 ZIP codes in Louisiana by 273,913 people, from the 1,080,456 expected as of July 2007 in the absence of Katrina to the 806,545 estimated as of July 2007 after Katrina struck (Table 2). This is a 25.35 percent reduction.

As can be seen by comparing Tables $\mathbf{3}$ and $\mathbf{4}$, the black population (Table 3 ) of these 55 ZIP codes was reduced both absolutely and relatively more than the white population (Table 4). The black population experienced a 32.68 percent loss (from 459,116 to 309,084 , a loss of 150,032 ) compared to a 19.78 percent reduction in the white population (from 545,133 to 437,288 , a loss of 107,845 ).

Although we do not show the tables due to space limitations, we note some results by gender and age (data available 
Table 3. 2007 Black Population Estimates by Parish in Louisiana: Difference Between Impact \& Baseline*

\begin{tabular}{|c|c|c|c|c|}
\hline \multirow{2}{*}{ PARISH } & \multicolumn{2}{|c|}{ Black Population Estimate } & \multicolumn{2}{|c|}{ Difference } \\
\hline & Impact & Baseline & Absolute & Percent \\
\hline Jefferson (17 zipcodes) & 127,352 & 112,021 & 15,331 & $13.69 \%$ \\
\hline Orleans (18 zipcodes) & 153,269 & 320,413 & $-167,144$ & $-52.17 \%$ \\
\hline Plaquemines (6 zipcodes) & 5,837 & 7,769 & $-1,932$ & $-24.87 \%$ \\
\hline St. Bernard (5 zipcodes) & 6,913 & 5,457 & 1,456 & $26.67 \%$ \\
\hline St. Charles (9 zipcodes) & 15,713 & 13,457 & 2,256 & $16.77 \%$ \\
\hline TOTAL (55 zipcodes) & 309,084 & 459,116 & $-150,032$ & $-32.68 \%$ \\
\hline
\end{tabular}

* Parish values may not sum precisely to TOTAL because of rounding.

Table 4. 2007 White Population Estimates by Parish in Louisiana: Difference Between Impact \& Baseline*

\begin{tabular}{|c|c|c|c|c|}
\hline PARISH & \multicolumn{2}{|c|}{ White Population Estimate } & \multicolumn{2}{|c|}{ Difference } \\
\hline Orleans (18 zipcodes) & 96,958 & 121,270 & $-24,312$ & $-20.05 \%$ \\
\hline Plaquemines (6 zipcodes) & 21,870 & 20,866 & 1,004 & $4.81 \%$ \\
\hline St. Charles (9 zipcodes) & 34,895 & 34,675 & 220 & $0.64 \%$ \\
\hline TOTAL (55 zipcodes) & 437,288 & 545,133 & $-107,845$ & $-19.78 \%$ \\
\hline
\end{tabular}

* Parish values may not sum precisely to TOTAL because of rounding.

upon request). Males and females were reduced at about the same level as the total population, about 25 percent. Similarly, other than the youth dependent and frail elderly populations, which both experienced a 27 percent reduction, the relative losses by age group were also around 25 percent.

\section{III.B. MISSISSIPPI}

As can be seen in Table 5, three ZIP code areas containing low-lying areas along the Gulf Coast bore the brunt of Katrina's landfall in Mississippi and its demographic impact. ZIP code 39520 (Bay Saint Louis, Hancock County) is estimated to have been hit the hardest in terms of its relative population loss, which was 8,366 people $(44.7 \%)$, from 18,760 to 10,374 . Four of the twenty-four Mississippi ZIP codes experienced population gains in terms of what was expected as of July 2007 in the absence of Katrina.

Table 6 provides the summary effects of Katrina by examining the difference between the Katrina-impacted estimate of the total population and the estimate in the absence of Katrina we examined for the six ZIP codes in Hancock County, the eleven ZIP codes in Harrison County, and the seven ZIP codes in Jackson County, respectively. We estimate that Hurricane Katrina led to a reduction of 13,111 people in the six ZIP codes in Hancock County, which is 31.73 percent less than the 41,324 expected in these five ZIP codes in the absence of Katrina as of 2007. For the 11 ZIP codes in Harrison County, the effect is estimated to be a reduction of 22,323 people, which is 10.55 percent less than the 211,537 expected in these ZIP codes in the absence of Katrina. The effect of Katrina on the seven ZIP codes in Jackson County is less than in Hancock and Harrison counties, both absolutely and relatively: a reduction of 1,803 , which is 1.38 percent less than the 130,961 expected in these ZIP codes in the absence of Katrina. Over all of the 24 ZIP codes in Mississippi, Katrina is estimated to have reduced the population by 37,237 people, from 383,633 to 346,545 as of July of 2007. This represents a 9.70 percent reduction.

As can be seen by comparing Tables $\mathbf{7}$ and $\mathbf{8}$, the white population (Table 8) of the twenty-four ZIP codes examined in Mississippi was reduced both absolutely and relatively more than the black population (Table 7), with a 10.28 percent loss (from 280,187 to 251,735 or a loss of 28,812 ) compared to a 6.26 percent reduction (from 79875 to 74,872 or a loss of 5,003).

Similar to what was found for the white population, in spite of the overall loss of the black population, seven ZIP codes experienced gains in their black populations relative to what was expected in the absence of Katrina.

As with the Louisiana data, we do not show tables by gender and age in the interest of brevity, but we do provide some summary statistics (data available upon request). In Mississippi, males and females were reduced at about the 
Table 5. 2007 Total Population Estimates by County, Place \& Zip Code in Mississippi: Difference Between Impact \& Baseline*

\begin{tabular}{|c|c|c|c|c|c|c|}
\hline \multirow{2}{*}{ County } & \multirow{2}{*}{ ZIP Code } & \multirow{2}{*}{ Name } & \multicolumn{2}{|c|}{ Total Population Estimate } & \multicolumn{2}{|c|}{ Difference } \\
\hline & & & Impact & Baseline & Absolute & Percent \\
\hline Hancock & 39525 & Diamondhead & 6,725 & 7,108 & -383 & $-5.39 \%$ \\
\hline Hancock & 39529 & Stennis Space Ctr. & 0 & 0 & N/A & N/A \\
\hline Hancock & 39572 & Pearlington & 1,198 & 1,887 & -689 & $-36.52 \%$ \\
\hline Hancock & 39576 & Waveland & 4,126 & 7,137 & $-3,011$ & $-42.19 \%$ \\
\hline Harrison & 39501 & Gulfport & 23,930 & 26,090 & $-2,160$ & $-8.28 \%$ \\
\hline Harrison & 39503 & Gulfport & 43,128 & 40,462 & 2,666 & $6.59 \%$ \\
\hline Harrison & 39532 & Biloxi & 25,852 & 28,763 & $-2,911$ & $-10.12 \%$ \\
\hline Harrison & 39534 & Biloxi & 3,273 & 3,396 & -123 & $-3.61 \%$ \\
\hline Harrison & 39540 & Diberville & 7,221 & 8,172 & -951 & $-11.64 \%$ \\
\hline Harrison & 39560 & Long Beach & 17,042 & 20,491 & $-3,449$ & $-16.83 \%$ \\
\hline Harrison & 39571 & Pass Christian & 13,144 & 16,313 & $-3,169$ & $-19.43 \%$ \\
\hline Harrison & 39574 & Saucier & 12,973 & 12,995 & -22 & $-0.17 \%$ \\
\hline Jackson & 39553 & Gautier & 18,504 & 17,732 & 772 & $4.35 \%$ \\
\hline Jackson & 39562 & Moss Point & 18,158 & 17,443 & 715 & $4.10 \%$ \\
\hline
\end{tabular}

*Numbers are subject to rounding.

Table 6. 2007 Total Population Estimates by County in Mississippi: Difference Between Impact \& Baseline*

\begin{tabular}{|c|c|c|c|c|}
\hline \multirow{2}{*}{ COUNTY } & \multicolumn{2}{|c|}{ Total Population Estimate } & \multicolumn{2}{c|}{ Difference } \\
\cline { 2 - 5 } & Impact & Baseline & Absolute & $-13,111$ \\
\hline \hline Hancock (6 zipcodes) & 28,213 & 41,324 & $-22,323$ & $-10.55 \%$ \\
\hline Harrison (11 zipcodes) & 189,214 & 211,537 & $-1,803$ & $-1.38 \%$ \\
\hline Jackson ( 7 zipcodes) & 129,158 & 130,961 & $-37,237$ & $-9.70 \%$ \\
\hline TOTAL (24 zipcodes) & 346,585 & 383,822 & & \\
\hline
\end{tabular}

* County values may not sum precisely to TOTAL because of rounding

same level as the total population, about 10 percent. Similarly, other than the youth dependent and frail elderly populations, which both experienced a 10 and 13 percent reduction, respectively the relative losses by age group were around 9 percent. Basically the same ZIP codes experiencing gains in the total population and the black and white populations also experienced gains by gender and in these age groups, while the remaining ZIP codes experienced losses by gender and in all of the same age groups.

\section{III.C. SUMMARY EFFECTS}

Over all 79 ZIP codes, Katrina is estimated to have reduced the "expected" population by 311,150 people, from $1,464,280$ to $1,153,130$ as of July 2007 . This represents a 
Table 7. 2007 Black Population Estimates by County in Mississippi: Difference Between Impact \& Baseline*

\begin{tabular}{|c|c|c|c|c|}
\hline \multirow{2}{*}{ COUNTY } & \multicolumn{2}{|c|}{ Black Population Estimate } & \multicolumn{2}{c|}{ Difference } \\
\cline { 2 - 5 } & Impact & Baseline & Absolute & $-1,678$ \\
\hline \hline Hancock (6 zipcodes) & 1,672 & 3,350 & $-2,538$ & $-50.09 \%$ \\
\hline Harrison (11 zipcodes) & 43,263 & 45,801 & -786 & $-5.54 \%$ \\
\hline Jackson (7 zipcodes) & 29,937 & 30,723 & $-5,003$ & $-6.26 \%$ \\
\hline TOTAL (24 zipcodes) & 74,872 & 79,875 & & \\
\hline
\end{tabular}

* County values may not sum precisely to TOTAL because of rounding

Table 8. 2007 White Population Estimates by County in Mississippi: Difference Between Impact \& Baseline*

\begin{tabular}{|c|c|c|c|c|}
\hline \multirow{2}{*}{ COUNTY } & \multicolumn{2}{|c|}{ White Population Estimate } & \multicolumn{2}{|c|}{ Difference } \\
\hline & Impact & Baseline & Absolute & Percent \\
\hline Hancock (6 zipcodes) & 25,717 & 36,328 & $-10,611$ & $-29.21 \%$ \\
\hline Harrison (11 zipcodes) & 132,208 & 149,589 & $-17,381$ & $-11.62 \%$ \\
\hline Jackson ( 7 zipcodes) & 93,450 & 94,270 & -820 & $-0.87 \%$ \\
\hline TOTAL (24 zipcodes) & 251,375 & 280,187 & $-28,812$ & $-10.28 \%$ \\
\hline
\end{tabular}

* County values may not sum precisely to TOTAL because of rounding

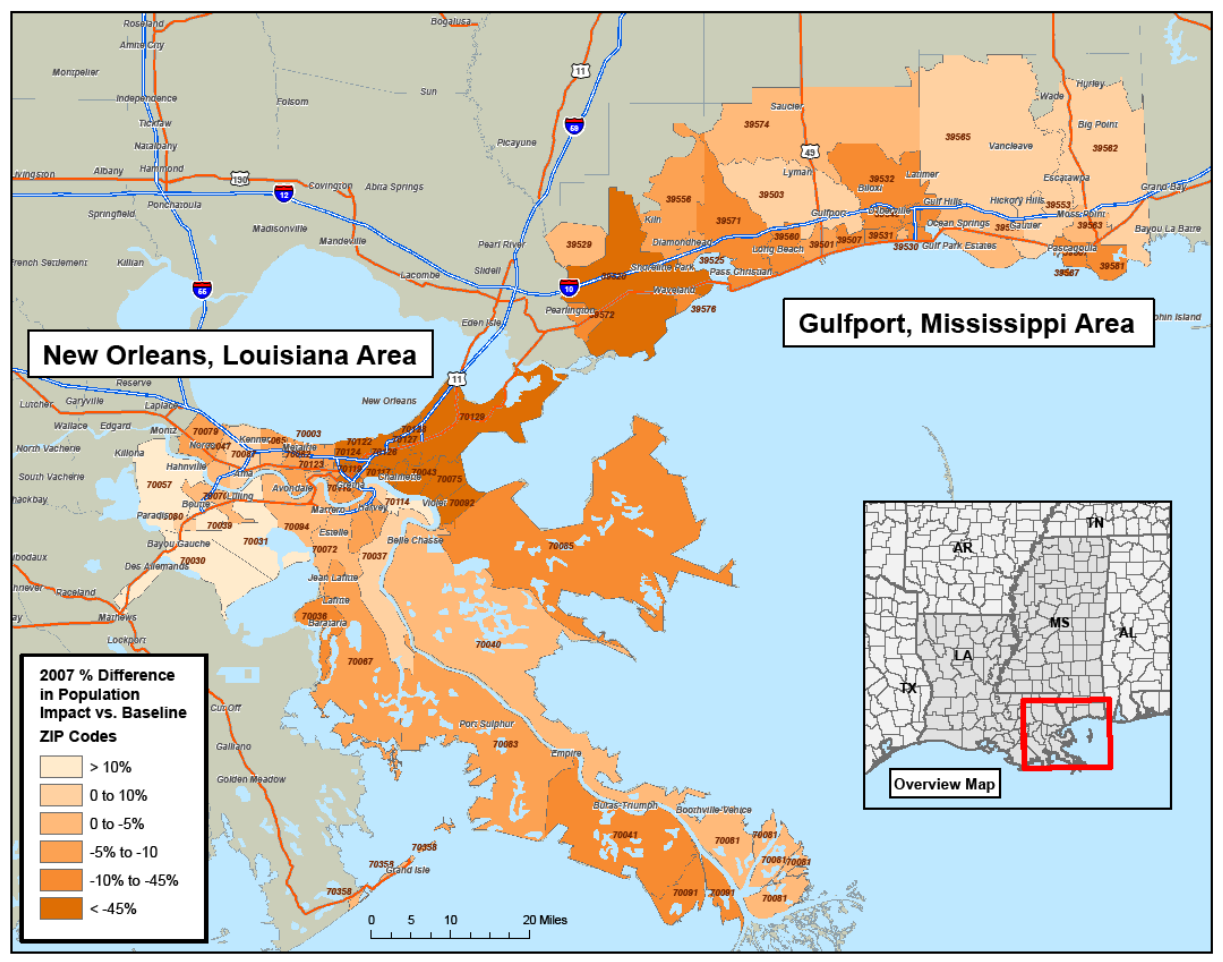

Fig. (2). Total population reduction (\%) in the study area due to katrina.

21.25 percent reduction. Fig. (2) displays this in visual form. The black population is estimated to have been reduced by 155,035 in these 79 ZIP codes, from 538,991 to 383.956, a 28.76 percent loss (Fig. 3). The white population is estimated to have been reduced by 136,657 , from 825,320 to 688,663 , a 16.56 percent reduction (Fig. 4).
Males and females are estimated to have been reduced by about 21 percent, the same rate as the total population. With the exceptions of the youth dependent age group (ages 0 to 14) and the frail elderly age group (85 years and over), age groups of interest also experienced around a 20 to 21 percent reduction. The youth dependent population and frail elderly 


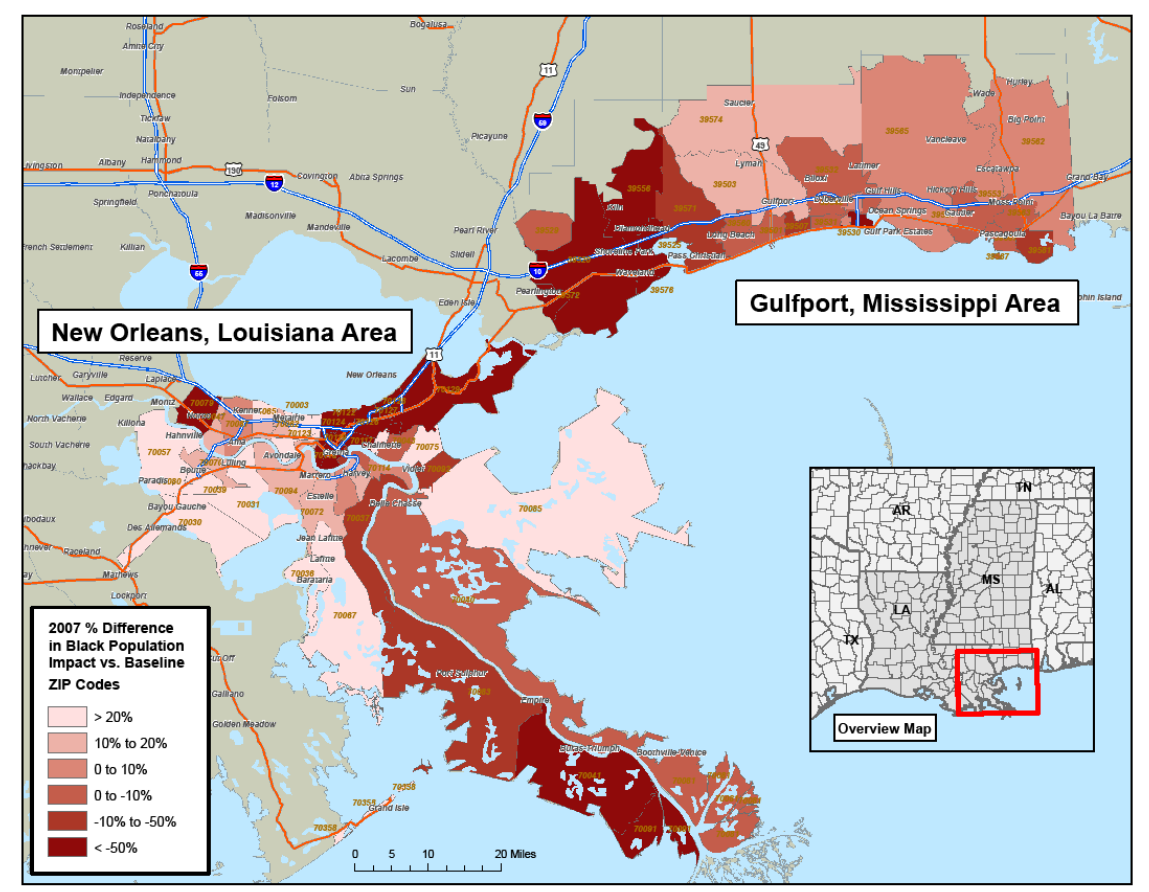

Fig. (3). Black population reduction (\%) in the study area due to Katrina.

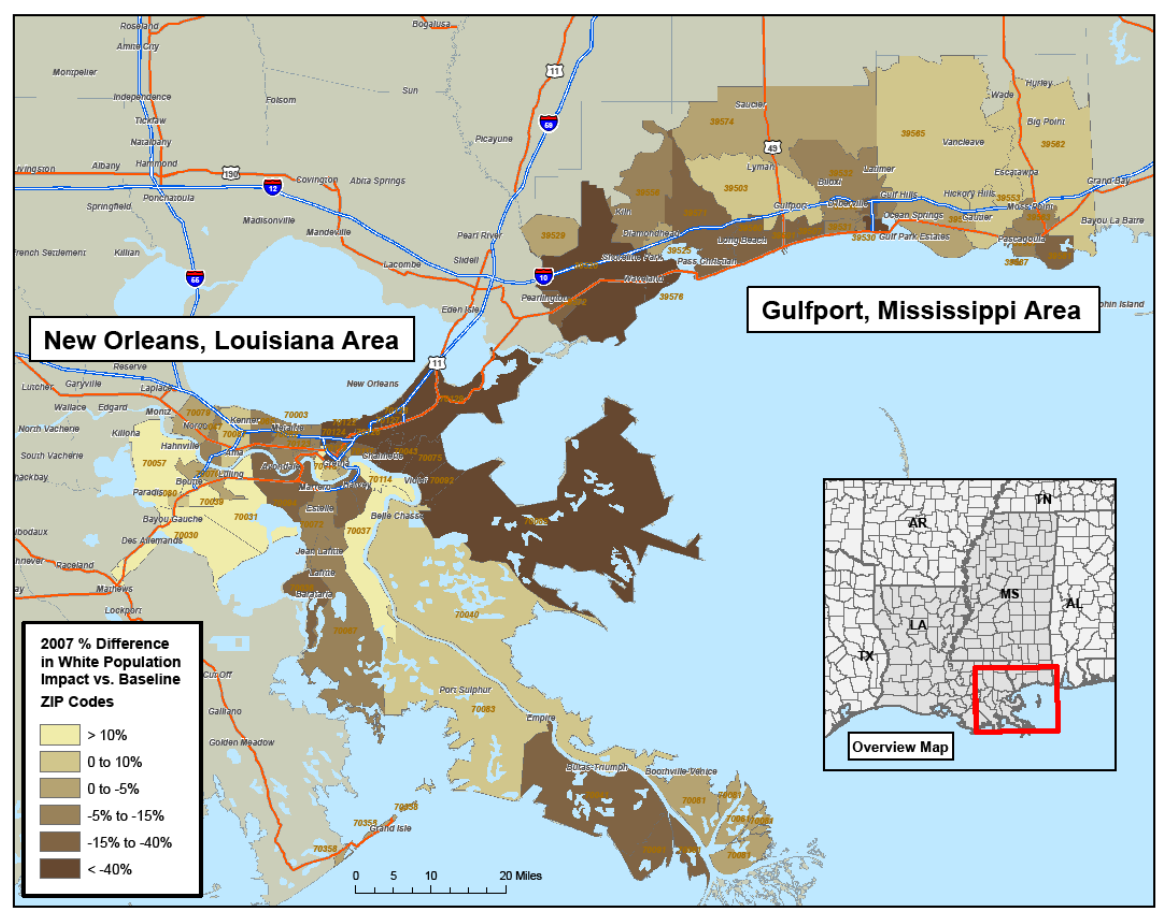

Fig. (4). White population reduction (\%) in the study area due to katrina.

were slightly higher with reductions of 23 and 25 percent, respectively.

The most striking difference between Louisiana and Mississippi is in terms of race. The black population of the 55 ZIP codes examined in Louisiana was reduced both absolutely and relatively more than the white population, with a 32.68 percent loss (from 459,116 to 309,084 , a loss of 150,032) compared to a 19.78 percent reduction (from
$545,133$ to 437,288 , a loss of 107,845$)$. In Mississippi, however, the losses by race are very different, where the white population in the 24 ZIP codes examined in Mississippi was reduced both absolutely and relatively more than the black population, with a 10.28 percent loss (from 280,187 to 251,735 a loss of 28,812 ) compared to a 6.26 percent reduction (from 79,875 to 74,872, a loss of 5,003). Again, these results can be seen in Figs. (3 and $\mathbf{4}$ ). 


\section{DISCUSSION}

We believe that the 'impact' perspective we employ is particularly useful for purposes of assessing the effects of a large scale disaster into the future. Using this perspective in this paper suggests that in the case of Katrina's impact on the New Orleans area and the Mississippi Gulf coast, the effects of a disaster can be long-lasting. The demographic impacts of Katrina on the Mississippi Gulf coast will be apparent when data from the 2010 U.S. Census are released; it is our belief that they could well extend into the 2020 decennial census. Together with previous research [6], our research suggests that the demographic effects of Katrina (and Rita) are likely to be felt not only in the 79 ZIP codes we examined, but in areas of extended proximity like the parishes in the area of Baton Rouge, Louisiana, and the counties around Houston, Texas. We estimate a population loss of 311,000 people in our study area; these human lives did not simply disappear. Cossman finds that "agents of delay" have served to extend Katrina's effects on this same area and he argues that these same agents will be associated with future disasters, both natural and man-made [24]. This is a perspective that, like our empirical findings, appears to run contrary to the post-disaster "recovery machine," a hypothesis described by Pais and Elliot [25] that has roots in the growth machine hypothesis advanced by Molotch [26] and Logan and Molotech [27] ${ }^{1}$ We also believe that the "impact" perspective employed in this paper provides a useful way to analyze the demographic effects of a disaster. We have compared the estimated demographic effects of Katrina with estimates that are made in the absence of this disaster. Our use of the impact perspective is novel because socio-economic and environment impact analyses are typically done in advance of a planned impact, not after-the-fact as we have done here. We believe that concepts, perspectives, and tools of impact assessment of can be extended to unplanned natural disasters like Katrina, and we hope that this research is a useful first step. Using these tools would, for example, fit squarely within a recommendation made by Saenz and Peacock about the need to develop more comprehensive and meaningful mitigation planning relative to large scale disasters [28].

\section{ENDNOTE}

A critical review of the growth machine hypothesis is found in Jonas and Wilson [29].

\section{ACKNOWLEDGEMENTS}

We thank Kyle Watson at ESRI for GIS support and both the editor and reviewers for their helpful comments and suggestions.

\section{REFERENCES}

[1] Chappell W, Forgette R, Swanson D, Van Boening M. Determinants of government aid to Katrina survivors: evidence from survey data. South Econ J 2007; 74 (2): 344-62.

[2] Swanson DA, Forgette R, Van Boening M, Holley C, Kinnell A. Assessing Katrina's demographic and social impacts on the Mississippi gulf coast. J Mississippi Acad Sci 2007; 52(4): 228-42.
Swanson DA. The demographic effects of hurricane katrina on the mississippi gulf coast: an analysis by ZIP Code. J Mississippi Acad Sci 2008; 53(4): 213-31.

[4] Brinkley D. The great deluge: hurricane katrina, New Orleans, and the Mississippi gulf coast. New York, NY: Morrow/HarperCollins 2006.

[5] Van Heerden I ,Bryan M. The storm: what went wrong and why during Hurricane Katrina - the inside story from one Louisiana scientist. New York, NY: Viking 2006.

[6] Frey WH, Singer A. Katrina and rita impact on gulf coast populations: first census findings. Washington, DC: The Brookings Institution; 2006.

[7] Burdge R. The concepts, process, and methods of social impact analysis. Middleton, WI: Social Ecology Press 2006.

[8] Pol L, Thomas R. Demography for business decision making. New York, NY: Quorom Books 1997.

[9] Pol L, Thomas R. The demography of health and health care, $2^{\text {nd }}$ ed. New York: Plenum 2000.

[10] Siegel J. Applied demography: applications to business, government, law, and public policy. San Diego, California: Academic Press 2002.

[11] Swanson DA. Hurricane Katrina: a case study of its impacts on medical service providers and their client populations. Open Demogr J 2009; 2: 8-17.

[12] Thomas R. Marketing health services. Chicago, Inois: Health Administration Press 2005.

[13] Carlson J, Williams C, Swanson D. The development of small area socioeconomic data to be utilized for impact analysis: rural southern Nevada. High level radioactive waste management. In: proceedings of the 1990 international conference, American Nuclear Society and American Society of Civil Engineers, New York, NY; 1990; pp. 985-90.

[14] Erickson PA. A practical guide to environmental impact assessment. San Diego, California: Academic Press 1999.

[15] Finsterbusch K, Wolf, C. Eds. Methodology of social impact assessment. Stroudsburg, Pennsylvania: Dowden, Hutchinson, and Ross, Inc, 1981.

[16] Leistritz F, Murdock S. The socio-economic impact of resource development: methods for assessment. Boulder, Colorada: Westview Press 1981.

[17] Schmidt R, Swanson D, Barr C. Socioeconomic impacts of the proposed federal gaming Tax. Int J Public Adm 1997; 20: 1675-98.

[18] Asian Disaster Reduction Center. Total disaster risk management: good practices. Kobe, Japan: Asian Disaster Reduction Center; 2005. Available from: http://www.adrc.or.jp/publications/ TDRM2005/TDRM_Good_Practices/Index.html

[19] Wombold L. ESRI demographic update methodology: 2005/2010. ESRI white paper. Redlands, California: ESRI 2005.

[20] Wombold L. 2006a. ESRI Gulf Coast Updates Methodology: 2006/2011. ESRI white paper. Redlands, California: ESRI 2006.

[21] Smith S, Tayman J, Swanson D. Population projections for states and local areas: methodology and analysis. New York: Kluwer Academic /Plenum Press 2001.

[22] Wombold L. ESRI demographic update methodology: 2006/2011. ESRI white paper. Redlands, California: ESRI 2006

[23] Wombold L. ESRI demographic update methodology: 2007/2012. ESRI white paper. Redlands, California: ESRI 2007.

[24] Cossman R. Hurricane Katrina as a natural experiment of 'creative destruction'. J Mississippi Acad Sci 2007; 52(4): 281-5.

[25] Pais J, Elliot J. Places as recovery machines: vulnerability and neighborhood change after major hurricanes. Soc Forces 2008; 86 (4): $1415-53$

[26] Molotch H. The city as a growth machine. J Am Soc 1976; 82 (2): 309-30. 
[27] Logan J, Molotch H. Urban fortunes. Berkeley, CA: University of California Press 1987.

[28] Saenz R, Peacock W. Rural people, rural places, and the hidden costs of hurricane Katrina. Rural Real 2006; 1 (2).
[29] Jonas A, Wilson D, Eds. The urban growth machine: critical perspectives, two decades later. New York, NY: State University of New York 1999.

Received: July 17, 2009

Revised: August 03, 2009

Accepted: August 08, 2009

(C) Swanson et al.; Licensee Bentham Open.

This is an open access article licensed under the terms of the Creative Commons Attribution Non-Commercial License (http://creativecommons.org/licenses/by-nc/3.0/) which permits unrestricted, non-commercial use, distribution and reproduction in any medium, provided the work is properly cited 